\title{
INDICADORES PARA EVALUAR LAS HABILIDADES MOTRICES EN EL PRIMER CICLO DEL NIVEL DE ENSEÑANZA PRIMARIO
}

\author{
INDICATORS FOR MOTOR SKILLS' EVALUATION DURING \\ THE FIRST CYCLE OF ELEMENTARY EDUCATION
}

\author{
INDICADORES PARA AVALIAR HABILIDADES MOTORAS NO \\ PRIMEIRO CICLO DO ENSINO FUNDAMENTAL
}

\author{
Leonardo Durruthy Rodríguez ${ }^{1}$ \\ Kenia Pérez Martí
}

\section{Resumen}

Este artículo derivado de investigación plantea una propuesta de indicadores para evaluar las habilidades motrices básicas: correr, saltar, lanzar y la capacidad coordinativa de acoplamiento en la asignatura Educación Física, en el primer ciclo de la educación primaria. Después de un estudio del sistema actual de evaluación en este nivel, consideramos que de acuerdo con la exigencia que deben cumplir los profesores de Educación Física para el logro de los objetivos por parte de los alumnos, estos objetivos pueden incorporar indicadores evaluativos que les permitan tener un mayor control de los alcances en los grados que integran el ciclo. Para ello se les asignan valores numéricos a los conocimientos teóricos de las habilidades, así como a la fluidez y efectividad de la acción motriz realizada, teniendo en cuenta que las habilidades seleccionadas son fundamentales para enfrentar en grados posteriores los deportes motivo de clases, proyectos y habilidades más complejas. El método experimental aplicado demostró que el profesor puede comparar los resultados, tanto teóricos como prácticos, obtenidos de un grado a otro, para así realizar una entrega pedagógica más objetiva al segundo ciclo. Este trabajo responde a la búsqueda de herramientas del profesional para hacer más efectivo y confiable su trabajo en consonancia con los requerimientos actuales, según los cuales el alumno es objeto y sujeto de su aprendizaje.

Pallabras clave: acoplamiento coordinativo; habilidades motrices; fluidez; indicadores de psicomotricidad; efectividad; ciclo

\section{Abstract}

This research paper presents a proposal of criteria to assess the basic motor skills: running, jumping, throwing, and the coordination adjustment ability in Physical Education during the first cycle of elementary education. After analyzing the current assessment system for this level, we believe that -in accordance with the requirement that Physical Education teachers must satisfy concerning their students' achievements-the course objectives can include assessment indicators which allow for a higher control of the goals reached in the grades of the cycle. For this purpose, the authors assigned numerical values to theoretical knowledge on the skills, as well as to fluency and effectiveness of the motor action performed. They took into consideration that the abilities chosen are essential to deal with more complex sports in class sessions, projects and skills in upper grades. The experimental approach applied showed that the teacher can compare the results-both practical and theoretical-obtained from one grade to another, so that he/she can make a more objective

1 Centro Universitario de Guántamo, Cuba. Correo electrónico: leonardodr@cug.co.cu

2 Joven Club de Computación y Electrónica, Cuba. Correo electrónico liorkis.arguello@gtm.jovenclub.cu 
pedagogical transition to the second cycle. This paper responds to the professionals' search for tools that make their job more effective and reliable, consistently with current requirements which consider the student as both learning subject and object.

Keywords: coordination adjustment; motor skills; fluency; psychomotricity indicators; effectiveness; cycle

\section{Resumo}

Este artigo derivado da pesquisa propõe uma proposta de indicadores para avaliar as habilidades motoras básicas: corrida, salto, arremesso e capacidade de coordenação do acoplamento na disciplina Educação Física, no primeiro ciclo do ensino fundamental. Após um estudo do atual sistema de avaliação neste nível, consideramos que, de acordo com a exigência que os professores de Educação Física devem cumprir para atingir os objetivos pelos alunos, esses objetivos podem incorporar indicadores de avaliação que lhes permitam ter maior controle dos alcances nos graus que compõem o ciclo. Para isso, valores numéricos são atribuídos ao conhecimento teórico das habilidades, bem como à fluidez e efetividade da ação motora realizada, levando em conta que as habilidades selecionadas são fundamentais para enfrentar nas séries posteriores os esportes das aulas, projetos e habilidades mais complexas. 0 método experimental aplicado mostrou que o professor pode comparar os resultados, tanto teóricos quanto práticos, obtidos de um grau ao outro, a fim de fazer uma entrega pedagógica mais objetiva ao segundo ciclo. Este trabalho responde à busca de ferramentas profissionais para tornar seu trabalho mais efetivo e confiável, de acordo com as exigências atuais, segundo as quais o aluno é objeto e sujeito de sua aprendizagem.

Palavras chave: acoplamento coordenativo; habilidades motoras; fluidez; indicadores psicomotores; eficácia; ciclo

Fecha de recepción: 16 de marzo de 2018

Fecha de evaluación: 2 de junio de 2019

Para citar este artículo:

Durruthy, L., y Pérez, K. (2018). Indicadores para evaluar las habilidades motrices en el primel ciclo del nivel de enseñanza primario. Lúdica Pedagógica, 28, 69-77. 


\section{INTRODUCCIÓN}

El perfeccionamiento de los programas de Educación Física que se produjeron en la década de los años ochenta revolucionó las clases al incorporar un programa que transita por los diferentes niveles de enseñanza, mediante un sistema de objetivos que los estudiantes deben alcanzar en cada grado del Sistema Nacional Educación de Cuba.

El primer ciclo del nivel de educación primario tiene como objetivo fundamental la enseñanza y el aprendizaje de las habilidades motrices básicas, así como el desarrollo de las capacidades físicas condicionales, culminando con las capacidades coordinativas, los juegos predeportivos y como deporte el atletismo. Los métodos propuestos son los específicos de la asignatura: expositivo-demostrativo, repetición, sintético, entre otros, con una concepción metodológica del juego. El nivel de desarrollo para adquirir las habilidades es de forma gruesa y en el de asimilación predomina el reproductivo.

Han transcurrido más de treinta años y los avances en las ciencias de la pedagogía y la didáctica han influido también en la educación física, donde surgen nuevas corrientes para el proceso de enseñanza-aprendizaje. Hoy se asume una pedagogía participativa, se recomienda una didáctica más activa en las clases, se incorporan métodos productivos de formación general y específicos para la asignatura, con los que se busca que el estudiante tenga un papel protagónico en su aprendizaje. Surgen nuevos conceptos y líneas por seguir, se habla de motricidad, se aplican estilos productivos que permiten desarrollar en los estudiantes, la mayor cantidad posible de aspectos educativos e instructivos.

En el material que ofrecemos el profesor podrá llevar un control y una evaluación más efectivos, partiendo de los objetivos que los estudiantes deben lograr, propiciando también su participación en la evaluación de los contenidos y objetivos propuestos.

La fluidez y efectividad de la acción motriz permiten que se pueda adquirir la habilidad motora con menos errores y se logre el hábito que de forma sintética une todos los elementos que la componen.

En el presente trabajo no pretendemos lograr un tecnicismo de las habilidades motrices que debe aprender el niño en este nivel de enseñanza, pero sí dar respuesta al cumplimiento de los objetivos y que cuando culmine este ciclo esté preparado para enfrentar un contenido con una exigencia superior en los deportes con pelotas y el atletismo. La carrera en línea recta, el salto natural y el lanzamiento a distancia con precisión son antecedentes que sirven de transferencia a las habilidades que tendrán que dominar en baloncesto, béisbol y con mayor exigencia en los eventos de atletismo en el segundo ciclo, es decir, no puede haber deficiencias en el logro de los objetivos; para ello su control y evaluación son básicos.

Las capacidades coordinativas comienzan a desarrollarse desde los primeros grados, por lo que consideramos que la capacidad de acoplamiento, por sus características, desempeña un papel determinante en acoplar habilidades y capacidades en una misma acción, por tanto la tomamos para evaluar el grado de desarrollo alcanzado al culminar el cuarto grado y tener una mayor visión de lo adquirido.

El diagnóstico realizado en estos grados mediante la observación y después de evaluar los resultados nos hizo comprender que si queremos dar clases con los requisitos de la contemporaneidad y actualidad de la pedagogía y didáctica tenemos que superar las siguientes deficiencias que son la base de nuestra investigación:

- Insuficiente nivel de desarrollo de las habilidades motrices básicas alcanzado en el primer ciclo, así como el control y vencimiento de los objetivos, según el programa.

- Deficiente transmisión de conocimientos teóricos de los contenidos.

- Falencias en la aplicación de los componentes de la clase contemporánea.

- Falta de fluidez y efectividad en las acciones relativas a las habilidades motrices de correr, saltar, lanzar y la capacidad coordinativa de acoplamiento.

Las insuficiencias expuestas nos llevaron a adelantar la investigación "Elaboración de indicadores para evaluar la asimilación de las habilidades motrices básicas: correr, saltar, lanzar, la capacidad coordinativa de acoplamiento y el conocimiento teórico en el 
proceso de enseñanza-aprendizaje en el primer ciclo del nivel de educación primario".

\section{TAREAS INVESTIGATIVAS}

Determinar los fundamentos que sustentan el control y la evaluación del proceso de enseñanza-aprendizaje de las habilidades motrices básicas durante el primer ciclo del nivel de educación primario.

Realizar un diagnóstico para determinar la situación actual del proceso de enseñanza-aprendizaje de las habilidades motrices básicas y el conocimiento teórico de estas.

Elaborar indicadores que permitan controlar y evaluar el proceso de enseñanza-aprendizaje de las habilidades motrices básicas y el conocimiento teórico en el primer ciclo.

Demostrar la factibilidad de los indicadores a través del experimento.

Determinar los fundamentos que sustentan el control y la evaluación del proceso de enseñanza-aprendizaje de las habilidades motrices básicas durante el primer ciclo del nivel de educación primario.

La evaluación en el primer ciclo se lleva a cabo mediante la observación y el control sistemático del desarrollo que obtienen los alumnos en los contenidos de cada unidad del programa. El maestro aprecia el comportamiento de los alumnos en las diferentes actividades programadas $\mathrm{y}$, a la vez, ejerce el control para determinar el nivel de los logros alcanzado en un periodo de tiempo, sobre la base de los ejercicios fundamentales de las unidades del programa y en correspondencia con los objetivos previstos para cada etapa. Es recomendable que los controles se realicen después de la segunda mitad de cada periodo; esto, unido a la observación del trabajo de los niños, permitirá al profesor una efectiva evaluación. También pondrá al descubierto la insuficiencia que puede existir en el proceso de enseñanza aprendizaje para efectuar las correcciones correspondientes, a partir de las categorías: E, MB, B, R

\section{Fundamentación teórica}

\section{Efectivo}

Una persona que hace las cosas bien en poco tiempo

\section{Fluido}

Según el Diccionario de la lengua española: "Que tiene facilidad de movimientos".

\section{Habilidad motriz}

Es la capacidad del sistema neuromuscular para controlar, regular y dirigir los movimientos, espacios corporales y temporales en las actividades físico-deportivas, que se expresa en la coordinación motriz inter- e intramuscular en estrecha unión con el sistema nervioso central. En ella, la calidad de los procesos, de la percepción, la representación y la memoria del individuo son determinantes para una correcta ejecución motriz del movimiento.

\section{Capacidad de acoplamiento o coordinación motriz}

Se define como las condiciones de rendimiento de un individuo para combinar en una estructura unificada de acciones, varias formas independientes de movimientos (Ruiz et al., 1985).

\section{Características generales del proceso de}

aprendizaje de las acciones motoras

En el proceso de aprendizaje de la acción motora distinguimos tres etapas:

1. Etapa de ejercitación inicial

2. Etapa de ejercitación profundizada

3. Etapa de fijación y perfeccionamiento ulterior

Alejandro López (2003) al abordar las tendencias de la educación física contemporánea tiene en cuenta los siguientes elementos de la pedagogía no directiva

- Alumno sujeto activo y constructor de su propio aprendizaje

- Tareas abiertas. Planteamientos globales y contextualizados.

- Métodos productivos

Fundamentar los objetivos y

contenidos de los programas

Primer grado

\section{Objetivos de la asignatura en el grado}

El profesor de Educación Física ha de trabajar para que los niños logren: 
- Desarrollar las habilidades motrices básicas y las capacidades físicas en correspondencia con las exigencias del grado.

Tercer grado

\section{Objetivos de la asignatura en el grado}

Los objetivos en el tercer grado están encaminados a que los alumnos puedan:

- Lograr un mayor desarrollo de las habilidades motrices básicas en estrecha relación con las capacidades físicas condicionales, coordinativas y de flexibilidad, haciendo énfasis en la coordinación de los movimientos, los ejercicios respiratorios y la postura adecuada al realizar las diferentes actividades.

\section{Gimnasia básica}

\section{Objetivos:}

1. Profundizar en el desarrollo de las capacidades físicas condicionales, coordinativas y de flexibilidad en correspondencia con las exigencias de grado, realizando las actividades, manteniendo una postura correcta, sentido del ritmo y orientación en el espacio.

- Saltos de longitud (sin y con carrera de impulso)

\section{Lanzamiento de béisbol a distancia}

- los niños han ejercitado el lanzamiento de la pelota a distancia a través de la unidad de gimnasia básica. En este grado se introduce como habilidad motriz deportiva.

\section{Cuarto grado}

Objetivos de la asignatura en el grado

El profesor ha de trabajar para que los alumnos logren:

- Incrementar el nivel de desarrollo de las capacidades físicas y habilidades motrices básicas e iniciar el aprendizaje de las habilidades motrices deportivas.

- Realizar las actividades físicas según su ritmo de ejecución, así como aplicarlo en diferentes combinaciones, orientándose en tiempo y espacio, manteniendo una postura adecuada.
- Comenzar la labor de formación vocacional y orientación profesional que despierten interés, motivaciones e inclinaciones hacia las actividades de la educación física y el deporte a través de los círculos de interés, movimiento de monitores y el desarrollo del contenido de la asignatura.

Gimnasia básica

Objetivos

1. Continuar desarrollando las habilidades motrices básicas y las capacidades físicas condicionales, coordinativas y de flexibilidad en correspondencia con los saltos:

- Salto de longitud natural

- Lanzar

- Carreras

- Atletismo

La evaluación en el primer ciclo se lleva a cabo mediante la observación y el control sistemático del desarrollo que obtienen los alumnos en los contenidos de cada unidad del programa. Mediante la observación, el maestro aprecia el comportamiento de los alumnos en las diferentes actividades programadas.

\section{Realizar un diagnóstico para determinar \\ la situación actual del proceso}

El diagnóstico se realizó en dos escuelas. En la primera trabaja un profesor con siete años de experiencia, y en la segunda una profesora que se graduó hace dos del nivel superior.

\section{Diagnóstico inicial}

Revisión de las evaluaciones del primer ciclo

- El control cuantificado y valorativo es muy limitado por lo que no permite determinar el cumplimiento de los objetivos de un grado a otro.

- La caracterización individual de los estudiantes es muy subjetiva con relación a los errores en las habilidades motrices.

- No valoran la asimilación del conocimiento adquirido en la asignatura. 
Evaluación de los indicadores

\begin{tabular}{|c|c|c|c|c|c|c|}
\hline Primer grado & Cant. & Fluidez & Efec. & $\%$ & C.T & \\
\hline Carrera en línea recta & 12 & 6 & 3 & 27 & 3 & 36 \\
\hline \multicolumn{7}{|l|}{ Tercer grado } \\
\hline Carrera en línea recta & 16 & 9 & 6 & 46 & 5 & 60 \\
\hline Salto de longitud & 16 & 4 & 7 & 33 & 3 & 27 \\
\hline Lanzamiento (dis., prec.) & 16 & 11 & 7 & 54 & 4 & 36 \\
\hline \multicolumn{7}{|l|}{ Cuarto grado } \\
\hline Carrera en línea recta & 26 & 11 & 8 & 57 & 6 & 50 \\
\hline Salto de longitud & 26 & 14 & 9 & 69 & 5 & 45 \\
\hline Lanzamiento (dis., prec.) & 26 & 13 & 9 & 66 & 5 & 45 \\
\hline
\end{tabular}

La capacidad de acoplamiento arrojó resultados nada significativos por lo que no tuvimos en cuenta los resultados del diagnóstico inicial para valorarlos y queda para un próximo estudio.

\section{Etapas de implementación del trabajo}

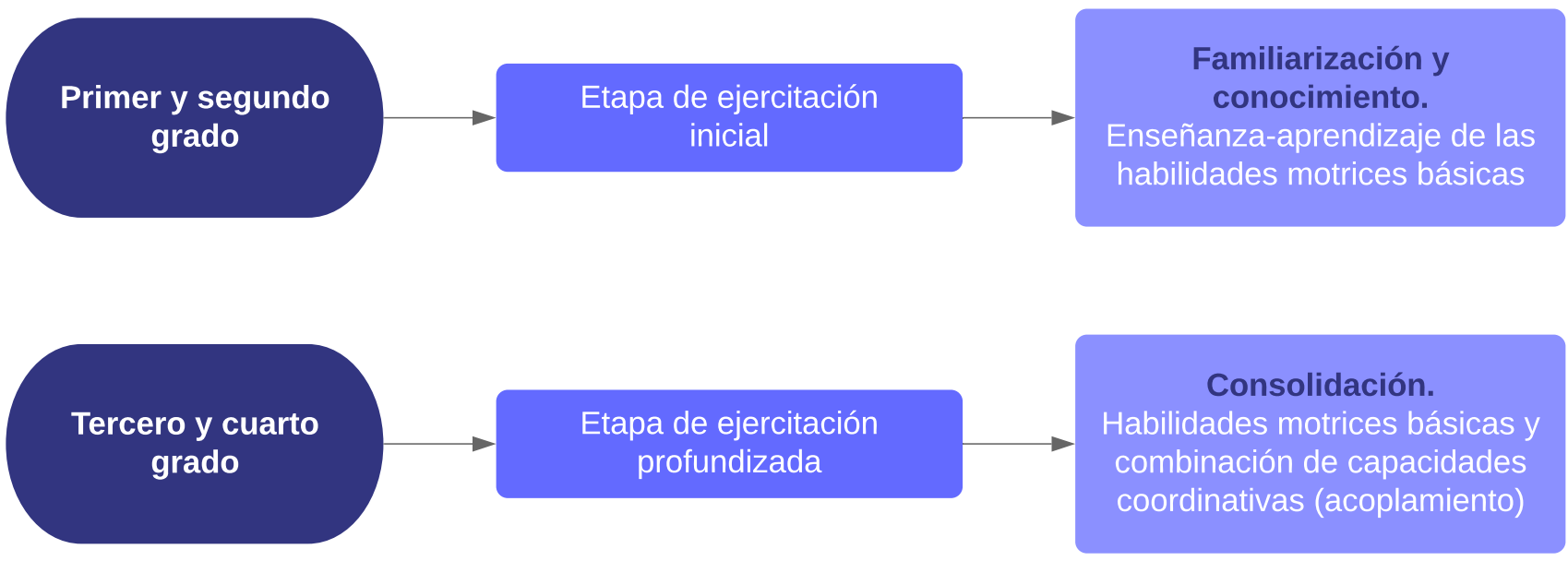

Indicadores de control y evaluación de las habilidades

\begin{tabular}{|l|c|}
\hline \multicolumn{2}{|c|}{ Carrera en línea recta } \\
\hline El tronco ligeramente inclinado hacia delante. & 3 \\
\hline La cabeza y el tronco en una misma línea. & 3 \\
\hline $\begin{array}{l}\text { El pie de apoyo hace contacto con la superficie del } \\
\text { terreno en la parte delantera del metatarso. }\end{array}$ & 3 \\
\hline En la fase de impulso la pierna debe quedar extendida totalmente. & 3 \\
\hline $\begin{array}{l}\text { El péndulo flexionado en la articulación de la rodilla y el } \\
\text { muslo moverlo hacia delante y arriba para que alcance } \\
\text { su mayor altura en el momento del impulso. }\end{array}$ & 3 \\
\hline
\end{tabular}




\begin{tabular}{|c|c|}
\hline $\begin{array}{l}\text { Los brazos flexionados en los codos y moverlos al mismo } \\
\text { ritmo que las piernas, pero alternadamente. }\end{array}$ & 3 \\
\hline Las manos deben estar relajadas y los dedos semiflexionados. & 3 \\
\hline Fluidez & 21 \\
\hline Máxima intensidad (efectividad) & 9 \\
\hline Total & 30 \\
\hline \multicolumn{2}{|l|}{ Salto de longitud } \\
\hline $\begin{array}{l}\text { Coordinación entre la carrera de impulso y el despegue. } \\
\text { Una adecuada carrera de impulso. }\end{array}$ & 3 \\
\hline Efectivo despegue vigorosamente sobre una marca. & 3 \\
\hline Enérgica elevación de los brazos y de la pierna de péndulo. & 3 \\
\hline $\begin{array}{l}\text { Las piernas unidas y flexionadas durante la primera parte del } \\
\text { vuelo y luego extendidas al frente al igual que los brazos }\end{array}$ & 3 \\
\hline Caída amortiguada. & 3 \\
\hline Impulsando el cuerpo hacia delante. & 3 \\
\hline Fluidez & 18 \\
\hline Efectividad & 12 \\
\hline Total & 30 \\
\hline \multicolumn{2}{|l|}{ Lanzamiento a distancia y precisión } \\
\hline Posición con las piernas en forma de paso. & 3 \\
\hline Ligera flexión de la pierna más atrasada. & 3 \\
\hline Lleva el brazo de lanzar hacia atrás. & 3 \\
\hline El tronco ligeramente arqueado & 3 \\
\hline $\begin{array}{l}\text { Efectúa la extensión de la pierna flexionada, el } \\
\text { enderezamiento del tronco y el movimiento rápido del } \\
\text { brazo por encima del hombro al lanzar la pelota. }\end{array}$ & 3 \\
\hline $\begin{array}{l}\text { El lanzamiento comienza con la extensión de la pierna } \\
\text { retrasada, proyección de la cadera hacia el área de } \\
\text { lanzamiento, trayendo el peso del cuerpo hacia el frente. }\end{array}$ & 3 \\
\hline $\begin{array}{l}\text { El brazo de lanzar se proyecta rápidamente por } \\
\text { encima del hombro de forma explosiva. }\end{array}$ & 3 \\
\hline Fluidez & 21 \\
\hline Efectividad & 9 \\
\hline Total & 30 \\
\hline Capacidad coordinativa de acoplamiento & 10 \\
\hline Total general de las habilidades & 130 \\
\hline
\end{tabular}


Control y evaluación de los conocimientos teóricos

\begin{tabular}{|l|c|}
\hline \multicolumn{1}{|c|}{ Carreras } & Evaluación \\
\hline Descríbeme cómo corres & 3 \\
\hline ¿Qué importancia tiene correr rápido? & 3 \\
\hline ¿Llegarás primero corriendo en línea recta o en zigzag? ¿Por qué? & 3 \\
\hline ¿Qué evaluación tiene el compañero que corrió? (coevaluación) & 3 \\
\hline \multicolumn{2}{|c|}{ Lanzamiento } \\
\hline Descríbeme el lanzamiento por encima del hombre que hiciste \\
\hline Qué entiende por lanzar con precisión & 3 \\
\hline En cuáles deportes se hace ese lanzamiento & 3 \\
\hline \multicolumn{1}{|c|}{ Salto longitud técnica natural } \\
\hline Descríbeme el salto que hiciste & 3 \\
\hline Qué importancia tienen las diferentes fases del salto & 3 \\
\hline Cuál es tu pierna de péndulo y de despegue & 3 \\
\hline Total & $\mathbf{2 1}$ \\
\hline
\end{tabular}

\section{Diseñar acciones que permiten controlar y evaluar} la efectividad y fluidez de las habilidades motrices

Para aplicar los indicadores que permiten medir el conocimiento teórico, la efectividad y fluidez de las habilidades motrices más la capacidad de acoplamiento se adelantaron las siguientes acciones metodológicas:

- Realizar una derivación de objetivos para cada elemento que integra la acción motriz, según los niveles de asimilación y desarrollo.

- Utilizar métodos, contenidos, medios que potencien el vencimiento de los objetivos.

Métodos más utilizados:

- Analítico-asociativo-sintético, repetición, juego y competencia.

Actividades que se incorporan:

Carrera en línea recta

- Carrera progresiva: 10 m, 15 m,20 m, 30 m

- Juego de correr elevando los muslos "el que gana pierde"
- El elegante de la pista

Saltos de longitud

- El campeón del salto sin impulso

- El rey del muellecito

- Corre y pisa la tabla

Lanzamiento a distancia y precisión

- Lanzar al blanco

- Reaccionar y lanzar

Capacidad de acoplamiento

- Quién hace lo que yo hago

- Salta y atrapa

\section{ANÁLISIS DE LOS RESULTADOS}

Después de aplicados los indicadores de efectividad y fluidez otorgándole un valor numérico para evaluar la adquisición de las habilidades motrices y el conocimiento teórico, se obtuvieron los siguientes resultados: 


\begin{tabular}{|c|c|c|c|c|c|c|}
\hline Primer grado & Cant. & Fluidez & Efec. & $\%$ & C. $\mathrm{T}$ & \\
\hline Carrera en línea recta & 12 & 14 & 7 & 27 & 10 & 83 \\
\hline \multicolumn{7}{|l|}{ Tercer grado } \\
\hline Carrera en línea recta & 16 & 17 & 8 & 75 & 11 & 98 \\
\hline Salto de longitud & 16 & 15 & 9 & 72 & 3 & 27 \\
\hline Lanzamiento (dis., prec.) & 16 & 16 & 7 & 81 & 7 & 63 \\
\hline \multicolumn{7}{|l|}{ Cuarto grado } \\
\hline Carrera en línea recta & 26 & 18 & 8 & 78 & 8 & 72 \\
\hline Salto de longitud & 26 & 16 & 9 & 75 & 8 & 72 \\
\hline Lanzamiento (dis., prec.) & 26 & 18 & 8 & 78 & 7 & 63 \\
\hline
\end{tabular}

\section{CONCLUSIONES}

El estudio realizado sobre el sistema de evaluación vigente en el primer ciclo de educación primaria y los objetivos que deben alcanzar los alumnos en los grados que lo conforman nos permitió aplicar indicadores con valores cuantitativos (fluidez y efectividad del movimiento) para evaluar los conocimientos teóricos y la adquisición de las habilidades motrices desarrolladas por los educandos.

El diagnóstico realizado arrojó insuficiencias en el control y la evaluación del cumplimiento de los objetivos, el trabajo metodológico permitió potenciar la calidad del proceso.

La puesta en práctica de los indicadores propuestos en las clases con un criterio de contemporaneidad, la aplicación del método de experimentación y la creación de un modelo para el control de los resultados demostraron la factibilidad de la propuesta.

\section{REFERENCIAS}

Acosta, M. y Perojo, A. E. I. (2003). Aplicación de la técnica de la rejilla, en contenidos del programa de sexto grado con alumnos de la escuela Enrique Hart Dávalos del municipio Arroyo Naranjo (tesis de doctorado) Instituto Superior de Cultura Física Manuel Fajardo, La Habana, Cuba.

Colectivo de autores de la Universidad de La Habana. (1995). Los métodos participativos: ¿una nueva concepción de la enseñanza? (Cap. 3, p. 300). Cuba: Editorial Universitaria.

Colectivo de autores del Instituto Superior de Cultura Física Manuel Fajardo. (1996). Teoría y práctica general de la gimnasia. Cuba: Editorial José Antonio Huelga.

López, A. (2003, en prensa). El proceso de enseñanza-aprendizaje en educación física. Hacia un enfoque integral físico educativo. La Habana: Inder.

Programas de Educación Física y orientaciones metodológicas del primer Ciclo. (2001). La Habana: Editorial Deportes.

Ruiz, A. (1985). Metodología de la enseñanza de la Educación Física. La Habana: Editorial Pueblo y Educación. 